\title{
Núcleo de estudos e defesa de direitos da infância e da juventude (NEDDIJ): amparo à proteção integral da criança e do adolescente
}

Área Temática Direitos Humanos e Justiça

\author{
Prof. ${ }^{\text {a }}$ Ms. Amália Regina Donegá ${ }^{1}$ \\ Bruna Cardoso de Freitas ${ }^{2}$ \\ Carlos Cristiano Meneguini de Oliveira ${ }^{3}$ \\ Carolina Pereira Spolador de Souza ${ }^{4}$ \\ Laísa Maria Pereira ${ }^{5}$ \\ Letícia Vier Machado 6 \\ Majoí Coquemalla Thomé7 \\ Rodrigo Ramires Ferreira ${ }^{8}$
}

\section{RESUMO}

O Núcleo de Estudos e Defesa de Direitos da Infância e da Juventude (NEDDIJ) é fruto do convênio celebrado entre a Universidade Estadual de Maringá-(UEM) e a Secretaria de Estado da Ciência, Tecnologia e Ensino Superior (SETI). Seu objetivo é consolidar uma estratégia de atendimento, defesa e garantia dos direitos individuais e coletivos das crianças e dos adolescentes economicamente hipossuficientes, residentes na Comarca de Maringá-PR, que se encontrem em situação de risco, ou tenham seus direitos violados ou ameaçados de serem violados, assim como daquele a quem se atribua a prática de atos

\footnotetext{
1 Mestre em Direito pela Universidade Estadual de Maringá. Coordenadora do Núcleo de Estudos e Defesa e de Direitos da Infância e da Juventude. Departamento de Direito Público da Universidade Estadual de Maringá. E-mail: ardonega@uem.br.

${ }^{2}$ Acadêmica do terceiro ano do curso de graduação em Direito da Universidade Estadual de Maringá (UEM). Estagiária bolsista no Núcleo de Estudos e Defesa de Direitos da Infância e da Juventude (NEDDIJ) pela Secretaria de Estado, Ciência, Tecnologia e Ensino Superior (SETI).

${ }^{3}$ Advogado bolsista no Núcleo de Estudos e Defesa de Direitos da Infância e da Juventude (NEDDIJ) pela Secretaria de Estado, Ciência, Tecnologia e Ensino Superior (SETI).

${ }^{4}$ Advogada bolsista no Núcleo de Estudos e Defesa de Direitos da Infância e da Juventude (NEDDIJ) pela Secretaria de Estado, Ciência, Tecnologia e Ensino Superior (SETI).

${ }^{5}$ Acadêmica do terceiro ano do curso de graduação em Direito da Universidade Estadual de Maringá (UEM). Estagiária bolsista no Núcleo de Estudos e Defesa de Direitos da Infância e da Juventude (NEDDIJ) pela Secretaria de Estado, Ciência, Tecnologia e Ensino Superior (SETI).

${ }^{6}$ Acadêmica do quinto ano do curso de graduação em Psicologia da Universidade Estadual de Maringá (UEM). Estagiária bolsista no Núcleo de Estudos e Defesa de Direitos da Infância e da Juventude (NEDDIJ) pela Secretaria de Estado, Ciência, Tecnologia e Ensino Superior (SETI).

${ }^{7}$ Acadêmica do quarto ano do curso de graduação em Direito da Universidade Estadual de Maringá (UEM). Estagiária bolsista no Núcleo de Estudos e Defesa de Direitos da Infância e da Juventude (NEDDIJ) pela Secretaria de Estado, Ciência, Tecnologia e Ensino Superior (SETI).

8 Psicólogo bolsista no Núcleo de Estudos e Defesa de Direitos da Infância e da Juventude (NEDDIJ) pela Secretaria de Estado, Ciência, Tecnologia e Ensino Superior (SETI).
} 
infracionais. Prezamos pela metodologia do trabalho interdisciplinar, prestando assistências jurídica e psicológica gratuitas. Por meio de ações intramuros e extramuros diversas, como palestras, conferências e pesquisas, o NEDDIJ busca socializar o conhecimento acadêmico para efetivar a tutela dos direitos da criança e do adolescente, bem como sensibilizar seus integrantes para o acolhimento e a humanização no atendimento ao público, integrando universidade e comunidade em um objetivo comum. Assim, suas ações permitem a descoberta de novos caminhos para o tratamento das questões que envolvam os direitos infanto-juvenis, permitindo a sua efetivação, bem como oferecem condições de acesso à Justiça nas situações em que se necessita de tutela judicial. A assistência jurídica prestada engloba ações socioeducativas, de guarda, adoção e tutela. A assistência psicológica compreende escuta e acolhimento, aconselhamento, pareceres e atendimentos. O NEDDIJ constitui-se, portanto, em instrumento contributivo no plano das políticas públicas para a infância e a juventude.

PALAVRAS-CHAVE: Direitos da Criança e do Adolescente. Tutela de Direitos. Estatuto da Criança e do Adolescente. Interdisciplinaridade.

\section{Desenvolvimento}

O Núcleo de Estudos e Defesa de Direitos da Infância e da Juventude (NEDDIJ) se justifica pelo respeito à garantia de acesso gratuito à justiça àquele cidadão que comprove insuficiência de recursos financeiros para arcar com tais custas, conforme preconiza o art. 5ํ, LXXIV da Constituição Federal. Por meio de convênio celebrado entre o Governo do Estado do Paraná, através da Secretaria de Estado da Ciência, Tecnologia e Ensino Superior, e a Universidade Estadual de Maringá, suas atividades tiveram início a partir do ano de 2006.

0 núcleo, visando à sensibilização e aperfeiçoamento técnico de recém-formados, é composto por equipe multidisciplinar, compreendendo dois advogados e um psicólogo, cotidianamente preparados para o ingresso no mercado de trabalho. 0 diferencial do trabalho do Núcleo é a preocupação com a formação dos profissionais que dele fazem parte, doravante sensíveis às questões de cunho social. Além disso, quatro estagiárias do curso de Direito e uma do curso de Psicologia dão corpo à equipe de trabalho, objetivando o acolhimento e a prestação de assistência jurídica e psicológica integral e eficiente. 
A população beneficiada pelo NEDDIJ são crianças e adolescentes economicamente hipossuficientes e residentes na Comarca de Maringá-PR, em favor da qual o NEDDIJ busca intervir por meio da defesa de seus direitos individuais e coletivos, atuando nas causas judiciais de seu interesse e realizando a defesa de adolescentes a quem é atribuída a prática de ato infracional, por meio da nomeação de seus advogados em processos judiciais.

As ações exclusivas do âmbito da Psicologia compreendem o suporte no atendimento ao público, realizando a escuta e o acolhimento da população, bem como o aconselhamento e atendimento psicológicos, a elaboração de laudos e pareceres quando solicitados pelo juiz ou pelos advogados. Estes últimos são fundamentados em metodologia e procedimentos válidos na área da Psicologia, como, por exemplo, entrevistas (semidirigida, lúdica).

No que tange à defesa dos adolescentes em cumprimento de medida socioeducativa, a Psicologia participa do acompanhamento de adolescentes inseridos no Programa Estadual Adolescente Aprendiz, através da realização de grupos de discussão sobre temas elencados pelos adolescentes em questão. Para prestar suporte necessário e efetivo, a Psicologia estabelece parcerias com outras instituições que operam nesta seara, a exemplo do Conselho Municipal de Direitos da Criança e do Adolescente (CMDCA) e do Centro de Socioeducação (Cense) de Maringá.

0 trabalho no âmbito da Psicologia destaca-se ao singularizar os atendimentos realizados, compreendendo todos os aspectos subjetivos que envolvem o conflito que nos é trazido, no intuito de levantar os componentes psicossociais complementando a compreensão jurídica dos fenômenos.

Com isso, reiteramos a necessária imprescindível assistência prestada pelo núcleo à comunidade, na ausência da Defensoria Pública no Estado do Paraná, na comarca, atuando de maneira semelhante a esta. Nesse sentido, busca-se efetivar a tutela dos direitos da criança e do adolescente, que, por motivos diversos, foram violados ou ameaçados, seja por conduta omissiva ou comissiva da família, da sociedade ou do Estado, sobretudo diante da falta de políticas públicas adequadas. Somado a essas ações instrumentais, não foge ao escopo do NEDDIJ o caráter acadêmico, materializado em projetos de ensino, pesquisa e extensão, além de um grupo semanal de discussões entre 
seus integrantes, durante o qual são abordados temas afins aos direitos infanto-juvenis. Para a realização dos trabalhos acadêmicos, faz-se uso do método teórico, bem como do método histórico, ao se analisarem e confrontarem as legislações anteriores referentes aos direitos de crianças e adolescentes que contribuíram para a elaboração do atual Estatuto da Criança e do Adolescente, referencial da doutrina da proteção integral. Igualmente, incentivamos a participação dos integrantes do núcleo em seminários e outros eventos atinentes ao nosso foco de trabalho.

O NEDDIJ não possui um teto de atendimentos ao público. No último ano, a equipe contemplou, em média, 45 atendimentos mensais ao público. Destes, resultaram 447 processos ativos, entre físicos e virtuais (Sistema Projudi). Entretanto, não restringimos nossos esforços aos dados quantitativos, pois assim estaríamos limitando-os. Os resultados produzidos pelo trabalho do NEDDIJ são processuais, atuando permanentemente na assistência, garantia e defesa dos direitos da criança e do adolescente.

Portanto, postas as atribuições intrínsecas que o núcleo exerce frente à demanda social, em um território ainda pouco sensível à temática dos direitos da criança e do adolescente, a despeito da violação constante de direitos exercida no país, é concreta a diferença produzida pelo NEDDIJ, garantindo, ainda que em meio a inúmeras dificuldades e empecilhos (territoriais, materiais, tecnológicos), a eficácia dos direitos fundamentais da comunidade da Comarca de Maringá.

Em síntese, o NEDDIJ adota a filosofia de que, para além dos instrumentos jurídicos que embasam a prática, qual seja, a Constituição da República Federativa do Brasil e o Estatuto da Criança e do Adolescente, ao investir na formação de tecnologia humana, estamos contribuindo para a consolidação de uma nova cultura quanto ao tratamento das questões infanto-juvenis, multiplicando as possibilidades de atuação e provocando, ainda que timidamente, avanços na participação de todos, Estado ou sociedade, em prol da proteção infanto-juvenil.

Por último, o NEDDIJ contribui para a efetivação do sistema de garantias de direitos da infância e da juventude no cenário paranaense, ao mesmo tempo que estimula a difusão e produção científica na área, servindo como legítimo instrumento de justiça social. 


\section{Referências}

BRASIL. Estatuto da criança e do adolescente. Brasília: Senado Federal, 1989.

NEDDIJ. O projeto. [2013]. Disponível em: <www.nedij.uem.br>. Acesso em: 5 jun. 2013. 